Article

\title{
Authentication of Herbal Medicines Dipsacus asper and Phlomoides umbrosa Using DNA Barcodes, Chloroplast Genome, and Sequence Characterized Amplified Region (SCAR) Marker
}

\author{
Inkyu Park ${ }^{1}$, Sungyu Yang ${ }^{1}$, Wook Jin Kim ${ }^{1}$, Pureum Noh ${ }^{1}$, Hyun Oh Lee ${ }^{2}$ \\ and Byeong Cheol Moon ${ }^{1, *(1)}$ \\ 1 Herbal Medicine Research Division, Korea Institute of Oriental Medicine, Daejeon 305-811, Korea; \\ pik6885@kiom.re.kr (I.P.); sgyang81@kiom.re.kr (S.Y.); ukgene@kiom.re.kr (W.J.K.); \\ pureum322@kiom.re.kr (P.N.) \\ 2 Phyzen Genomics Institute, Seongnam 13558, Korea; dlgusdh88@phyzen.com \\ * Correspondence: bcmoon@kiom.re.kr; Tel.: +82-42-868-9530
}

Received: 28 June 2018; Accepted: 15 July 2018; Published: 17 July 2018

\begin{abstract}
Dried roots of Dipsacus asper (Caprifoliaceae) are used as important traditional herbal medicines in Korea. However, the roots are often used as a mixture or contaminated with Dipsacus japonicus in Korean herbal markets. Furthermore, the dried roots of Phlomoides umbrosa (Lamiaceae) are used indiscriminately with those of $D$. asper, with the confusing Korean names of Sok-Dan and Han-Sok-Dan for D. asper and P. umbrosa, respectively. Although D. asper and P. umbrosa are important herbal medicines, the molecular marker and genomic information available for these species are limited. In this study, we analysed DNA barcodes to distinguish among D. asper, D. japonicus, and P. umbrosa and sequenced the chloroplast (CP) genomes of $D$. asper and D. japonicus. The CP genomes of D. asper and D. japonicus were 160,530 and $160,371 \mathrm{bp}$ in length, respectively, and were highly divergent from those of the other Caprifoliaceae species. Phylogenetic analysis revealed a monophyletic group within Caprifoliaceae. We also developed a novel sequence characterised amplified region (SCAR) markers to distinguish among D. asper, D. japonicus, and P. umbrosa. Our results provide important taxonomic, phylogenetic, and evolutionary information on the Dipsacus species. The SCAR markers developed here will be useful for the authentication of herbal medicines.
\end{abstract}

Keywords: plant species identification; oriental medicine; plastid; dipsaci radix; phlomidis radix

\section{Introduction}

Herbal medicines are widely used in oriental medicine. However, adulteration and contamination from related species, as well as from other genera, is a common problem [1]. In general, distinguishing authentic from inauthentic herbal products with the unaided eye is difficult. Thus, methods are needed to discriminate good quality herbal products from adulterated preparations.

Molecular tools are helpful in the accurate identification of species and authentication of herbal products. In plants, DNA barcoding has been used for species identification and for differentiating authentic herbal medicines from closely related species [2,3]. The nuclear ribosomal DNA (rDNA) internal transcribed spacers (ITS) region and $m a t K, r b c L$, and $p s b A-t r n H$ genes have been frequently used for plant species identification, as well as for phylogenetic and evolutionary analyses $[4,5]$. These DNA barcodes have only been used to discriminate among closely related species in several 
taxa. Moreover, identifying the authentic species based on a few sites of variable nucleotide sequences is difficult. Chloroplast (CP) genome sequencing is a potential alternative to DNA barcoding.

The next generation of sequencing platforms has enabled the complete sequencing of CP genomes, which has rapidly increased. The genomic information gained from sequencing projects has been used for plant species identification, high-resolution phylogenetic analysis, marker development to differentiate between closely related species, and the evolutionary analysis of CP structural variation, genome arrangement, and gene loss, including gene transfer from the CP to the nucleus or mitochondria [6-8]. CPs play an important role in photosynthesis, carbon fixation, and starch and fatty acid biosynthesis in plants [9,10]. In higher plants, the CP genome ranges from 100 to $180 \mathrm{~kb}$ in size and consists of 110-130 genes, including protein-coding genes and those encoding ribosomal RNAs (rRNAs) and transfer RNAs (tRNAs) [6]. Comparison of CP genomes has enabled the discovery of genetically variable regions that enable the distinguishing of species [11,12]. Insertion/deletion (Indel) mutations and single nucleotide polymorphisms in CP genomes have been frequently used for species identification $[11,13,14]$. Furthermore, the sequence characterised amplified region (SCAR) markers have been used to distinguish authentic herbal preparations from morphologically similar plant species [15], as these are simple, highly reproducible, and cheap. Thus, this method has been frequently used for species identification and the authentication of herbal medicines [15-18]. Sequence information is obtained from DNA fingerprints or barcodes, such as the presence or absence of amplicons, using sequence-specific primers and artificial polymorphic banding patterns.

Microsatellites or simple sequence repeats (SSRs) are abundant in genomes and have been widely used in phylogenetic analysis, population genetics, and molecular breeding [19,20]. Most SSRs are repeats of A or T units and account for the AT richness of the chloroplast genomes [21,22].

Dried roots of Dipsacus asper Wall. ex DC., commonly known as Dipsaci Radix ("Sok-Dan" in Korean), and Phlomoides umbrosa (Turcz.) Kamelin and Makhm., commonly known as Phlomidis Radix ("Han-Sok-Dan" in Korean), are used as important herbal medicines in Korea [23]. In Korean herbal pharmacopoeia, only the dried roots of $D$. asper and P. umbrosa are described as authentic Dipsaci Radix and Phlomidis Radix, respectively [23]. Unfortunately, the dried roots of D. japonicus Miq. are often mixed with those of $D$. asper and misused as Dipsaci Radix in Korean herbal markets because of the morphological similarities between them. In addition, the dried roots of P. umbrosa are also frequently used as economically motivated adulterants of Dipsaci Radix and are used for the same clinical purpose because of the confusing name and high cost of the authentic herb [24].

However, in traditional Korean medicine, Dipsaci Radix and Phlomidis Radix are used for different clinical purposes [25]. Dipsaci Radix is used for its protective effect against liver and kidney diseases, whereas Phlomidis Radix helps to discharge phlegm and heal bruises [23]. By contrast, the currently reported pharmacological effects of Dipsaci Radix and Phlomidis Radix are completely different. Dipsaci Radix is reported to have osteo-protective effects [26,27], whereas Phlomidis Radix is reported to have anti-inflammatory effects [28,29]. Therefore, indiscriminate application of these two herbal medicines can cause unforeseen side effects and threaten their use as medicines. Moreover, differentiating herbal medicines from adulterants is important to enhance their medicinal potential and safety and to ensure proper quality control of medicinal products.

D. asper and D. japonicus belong to the Caprifoliaceae family, which consists of 800 species in 42 genera worldwide [30]. D. asper is mainly distributed in the highland region (1500-3700 m above sea level) of China [31], whereas D. japonicus is distributed in Korea and Japan [23]. In general, D. asper is $2 \mathrm{~m}$ in height and has pinnatisect leaf blades, white or lemon yellow flowers, and a white, disk-shaped calyx with papillate-setose leaves. By contrast, D. japonicus is $1.5 \mathrm{~m}$ tall and has narrowly elliptic leaf blades, purplish red flowers, and a cup-shaped calyx with non-existent papillate-setose leaves. The Dipsacus species have a capitula [31]. The morphological traits of P. umbrosa (Lamiaceae) are different from those of Dipsacus species. P. umbrosa is $0.5-1 \mathrm{~m}$ in height and has verticillasters, tubular calyx, and white and pink flowers [23]. Although plants of D. asper, D. japonicus, and P. umbrosa can be easily distinguished based on their morphological differences, the dried roots of these species 
are difficult to distinguish with the unaided eye. Therefore, there is a need to distinguish between authentic Dipsaci Radix and Phlomidis Radix.

In this study, we analysed universal DNA barcodes to distinguish between D. asper, D. japonicus, and P. umbrosa. We also sequenced and characterised the CP genomes of D. asper and D. japonicus. Comparison of their $\mathrm{CP}$ genome structure and phylogenetic analysis revealed genetically divergent regions in Caprifoliaceae. Furthermore, we developed novel SCAR markers for distinguishing D. asper and D. japonicus from P. umbrosa. Our results provide valuable genomic information for the Dipsacus species and an in-depth insight into the evolution within Caprifoliaceae. These data will also enable the quality control of the valuable herbal medicines, Dipsaci Radix and Phlomidis Radix.

\section{Results and Discussion}

\subsection{Authentication of D. asper, D. japonicus, and P. umbrosa Using DNA Barcodes}

To distinguish among D. asper, D. japonicus, and P. umbrosa, we performed DNA barcode analysis using the nuclear rDNA ITS2, $m a t K$, and $r b c L$ regions. We sequenced a total of 12 samples among the three species and analysed the sequence alignments (Table 1). The ITS2 region and matK gene harbored the highest number of variable sites (ITS2 nucleotide diversity [Pi] $=0.12842$; mat $\mathrm{K} \mathrm{Pi}=0.10377$ ) of the three species. The Pi value of $P$. umbrosa was dramatically different from that of $D$. asper and D. japonicus. A comparison between the two Dipsacus species revealed only three $(0.2 \%)$ parsimony informative sites in $r b c L$ and seven (1.8\%) in ITS2. These data indicate that the universal DNA barcode regions of $D$. asper and D. japonicus are highly similar. DNA barcodes have been mainly used for discrimination among herbal medicine as well as for species identification $[17,18]$. A previous study using ITS1 and ITS2 regions showed that these sequences of $D$. asper are similar to those of $D$. japonicus, D. chinensis, and D. mitis [32]. However, these sequences are insufficient for the development of molecular markers, and P. umbrosa and the other DNA barcode regions were not included in this study. Although D. asper, D. japonicus, and P. umbrosa exhibit species-characteristic in DNA barcode regions, these cannot be applied to commercial herbal products because of the presence of adulterants. Therefore, to ensure the adequate quality control of herbal medicines, molecular markers are needed to distinguish among D. asper, D. japonicus, and P. umbrosa.

Table 1. The analysis of universal DNA barcodes in Dipsacus asper, D. japonicus, and P. umbrosa.

\begin{tabular}{|c|c|c|c|c|c|c|c|c|c|}
\hline \multirow{2}{*}{ Species } & \multirow{2}{*}{ DNA } & \multirow{2}{*}{$\begin{array}{c}\text { AL }^{1} \\
\text { Length } \\
\text { (bp) }\end{array}$} & \multicolumn{2}{|c|}{$\begin{array}{c}\text { Parsimony } \\
\text { Informative Sites }\end{array}$} & \multicolumn{2}{|c|}{ Variable Sites } & \multirow{2}{*}{$\begin{array}{c}\text { Nucleotide } \\
\text { Diversity } \\
\text { (Pi) }\end{array}$} & \multirow{2}{*}{$\begin{array}{l}\text { No. of } \\
\text { Indels }\end{array}$} & \multirow{2}{*}{$\begin{array}{c}\text { No. of } \\
\text { Haplotypes }\end{array}$} \\
\hline & & & No. & $\%$ & No. & $\%$ & & & \\
\hline \multirow{2}{*}{$\begin{array}{l}\text { D. asper vs. D. japonicus vs. } \\
\text { P. umbrosa }\end{array}$} & matK & 1276 & 234 & 18.3 & 242 & 19.0 & 0.10377 & 2 & 8 \\
\hline & $r b c L$ & 1511 & 106 & 7.0 & 113 & 7.5 & 0.0394 & 1 & 6 \\
\hline D. asper vs. D. japonicus & ITS2 & 379 & 7 & 1.8 & 9 & 2.4 & 0.00718 & 0 & 4 \\
\hline
\end{tabular}

\subsection{CP Genome Organisation of D. asper and D. japonicus}

We sequenced the $\mathrm{CP}$ genomes of $D$. asper and D. japonicus to distinguish between these species. Paired-end reads of D. asper $(2.1 \mathrm{~Gb})$ and $D$. japonicus $(2.2 \mathrm{~Gb})$ were trimmed to obtain 1.5 and $1.6 \mathrm{~Gb}$ datasets, respectively. Sequencing revealed the total $C P$ genome size of $D$. asper and $D$. japonicus as 160,530 and $160,371 \mathrm{bp}$, with $286 \times$ and $170 \times$ coverages, respectively (Table S1). Sequence reads were mapped onto the complete CP genomes (Figure S1). The CP genomes of both species were of high quality (Figure 1 and Table 2) and showed a quadripartite structure. Both chloroplast genomes were partly validated using polymerase chain reaction (PCR)-based sequencing (Table S2). Sequences of junctions between the four regions of the CP genome (large single copy (LSC)/inverted repeat (IRa), 
$\mathrm{IRa} /$ small single copy (SSC), SSC/IRb, and IRb/LSC) were aligned against the complete CP genome sequence (Table S3). The guanine-cytosine (GC) content of both species was $38.8 \%$.

In general, the GC content of the inverted repeat (IR) regions was higher than that of the LSC and SSC regions in both species. The gene content and gene order were similar in both species. The CP genomes of both species harbored 112 unique genes, including 79 protein-coding genes, 4 rRNA genes, and 29 tRNA genes. Eighteen genes were duplicated in the IR regions (Table S4). Fifteen genes, including $r p s 12$, harbored a single intron, whereas ycf3 and $\operatorname{lpP}$ carried two introns (Table S5). Alternative start codons, ACG in $n d h D$ and $p s b L$ and GTG in $r p s 19$, were identified. These codons are a general phenomenon in the CP genomes of land plants [33-35]. We also analysed the codon usage and anticodon recognition patterns in the two Dipsacus species. Dipsacus asper and D. japonicus harbored 23,482 and 23,826 codons, respectively, among which codons for leucine and serine were the most abundant (Figure S2 and Table S6). Relative synonymous codon usage (RSCU) values revealed a synonymous codon bias with a high proportion of $\mathrm{A}$ or $\mathrm{T}$ at the third nucleotide position (Figure S3). This phenomenon is consistent with that found in other angiosperms [36-39]. The CP genome structures of both Dipsacus species were similar to that of angiosperms [21,40,41]. Thus, the two CP genome sequences had a $99.57 \%$ similarity, but no differences in the $\mathrm{CP}$ genome structure or gene order were detected between the two species (Table 2).

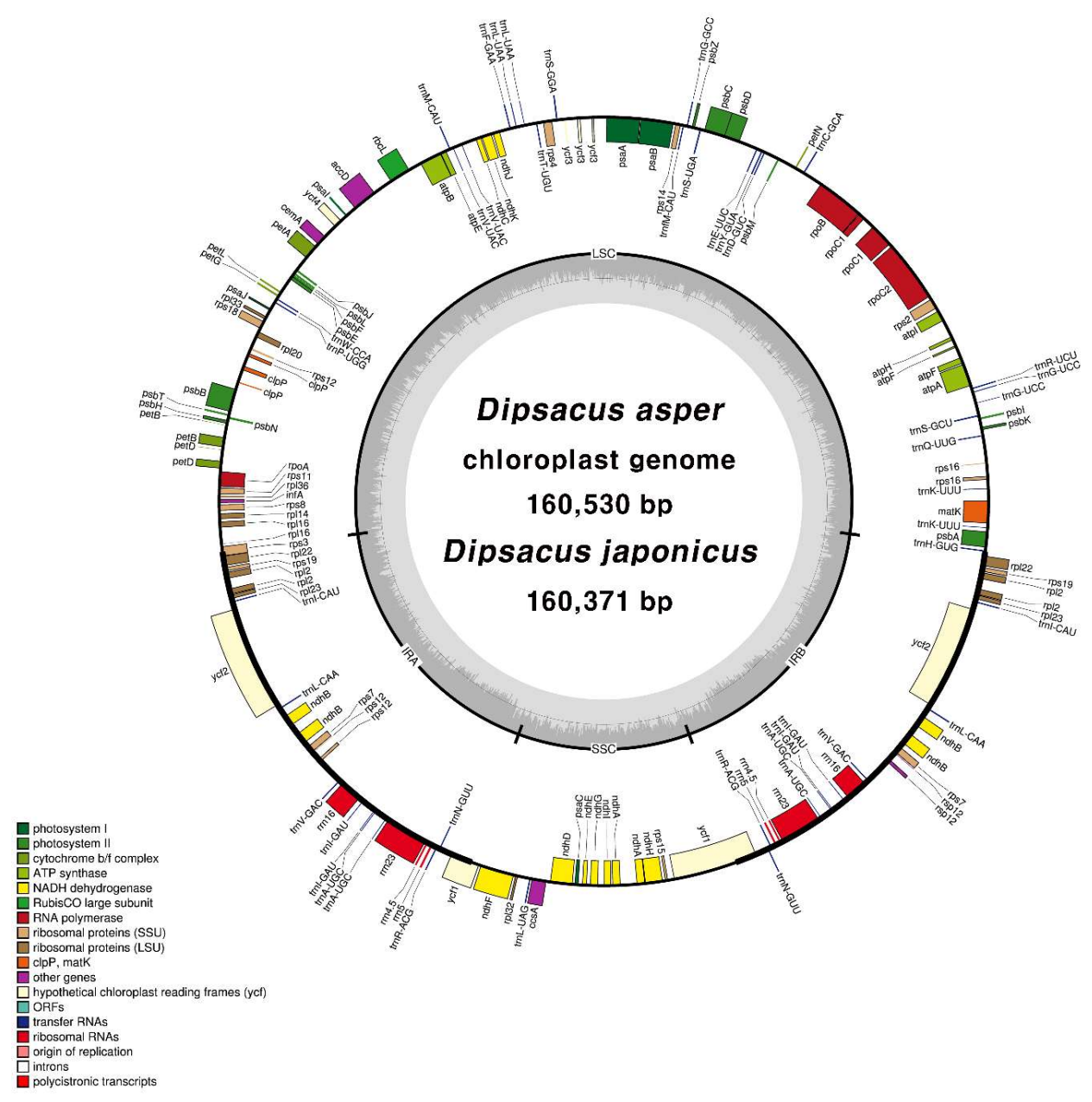

Figure 1. The circular gene map of Dipsacus asper and D. japonicus. The genes drawn inside the circle are transcribed clockwise, whereas those drawn outside the circle are transcribed counterclockwise. Dark gray shading inside the inner circle represents the GC content. LSC: large single copy; IR: inverted repeat; SSC: small single copy; GC: guanine-cytosine; ORF: open reading frame. 
Table 2. The characteristics of the chloroplast (CP) genomes of D. asper and D. japonicus.

\begin{tabular}{ccc}
\hline Characteristic & D. asper & D. japonicus \\
\hline Accession number & MH074864 & MH074865 \\
Total CP genome size (bp) & 160,530 & 160,371 \\
LSC region (bp) & 86,979 & 87,193 \\
IR region (bp) & 27,821 & 27,664 \\
SSC region (bp) & 17,909 & 17,850 \\
Number of genes & 112 & 112 \\
Protein-coding genes & 79 & 79 \\
rRNA & 4 & 4 \\
tRNA & 29 & 29 \\
Introns (bp) & 14,368 & 14,392 \\
Intergenic spacers (bp) & 50,578 & 51,526 \\
GC content (\%) & 38.8 & 38.8 \\
LSC (\%) & 37.2 & 37.1 \\
IR (\%) & 42.8 & 42.9 \\
SSC (\%) & 34.2 & 34.2 \\
\hline
\end{tabular}

CP: Chloroplast; LSC: Large single copy; IR: Inverted repeat; SSC: Small single copy.

\subsection{Analysis of Repeats in the CP Genomes of D. asper and D. japonicus}

In this study, 156 and 154 SSRs were detected in the CP genomes of D. asper and D. japonicus (Figure S4). Most of the mononucleotide SSRs in the Dipsacus species were present in the intergenic spacer (IGS) region (Figure S4A,B). In both species, the number of SSRs per unit length was higher in the single copy regions (LSC and SSC) than in the IR regions. Seven and five species-specific SSRs were identified in D. asper and D. japonicus, respectively. We also analysed the potential of polymorphic SSRs for marker development in the two Dipsacus species. Twenty-seven SSRs, polymorphic between the two species comprising A or T mononucleotides, were detected (Table S7). Structural variation in $\mathrm{CP}$ genomes, including gene duplication, gene expansion, and genomic rearrangement, result in abundant tandem repeat sequences [42]. A total of 37 and 34 tandem repeats were detected in the $C P$ genomes of $D$. asper and D. japonicus, respectively, of which 13 and 12 were short tandem repeats, respectively (Figure S5). Tandem repeats greater than $100 \mathrm{bp}$ in length were abundant in both species. Most tandem repeats occurred in exons and in the IGS region present within the LSC and IR regions of the chloroplast genomes. Three palindromic repeats, $25-33 \mathrm{bp}$ in length, were detected in both species (Table S8). Tandem repeats, which are variable in copy numbers between species, are often used as molecular markers $[13,14]$.

\subsection{Comparative Analysis of CP Genomes within Caprifoliaceae}

We compared the CP genome sequences of five plant species within the Caprifoliaceae family, including D. asper, D. japonicus, Patrinia saniculifolia, Kolkwitzia amabilis, and Lonicera japonica, to identify divergent regions (Figure 2). The CP genomes of D. asper and D. japonicus were highly conserved in the coding and non-coding regions, except for the $a c c D$ and $y c f 2$ genes, but were highly divergent from the other Caprifoliaceae species in the coding region. The divergence patterns of P. saniculifolia, K. amabilis, and L. japonica were similar to those of D. asper and D. japonicus. We compared the LSC, IRa, SSC, and IRb boundaries in the five species (Figure S6). The structure of the IR region was highly similar in the two Dipsacus species. The rpl3 gene extended into the IRa region in D. asper, D. japonicus, K. amabilis, and L. japonica. The ycf1 genes were located at the IRa/SSC and SSC/IRb junctions in D. asper, D. japonicus, and P. saniculifolia. Overall, the CP genomes of the five species were highly divergent in the IR regions. Contraction and expansion of the IR regions due to genomic rearrangement is a common phenomenon in angiosperms [43]. Further investigations are needed to dissect the structural variation in the chloroplast genomes and to understand the evolutionary relationships within Caprifoliaceae. 


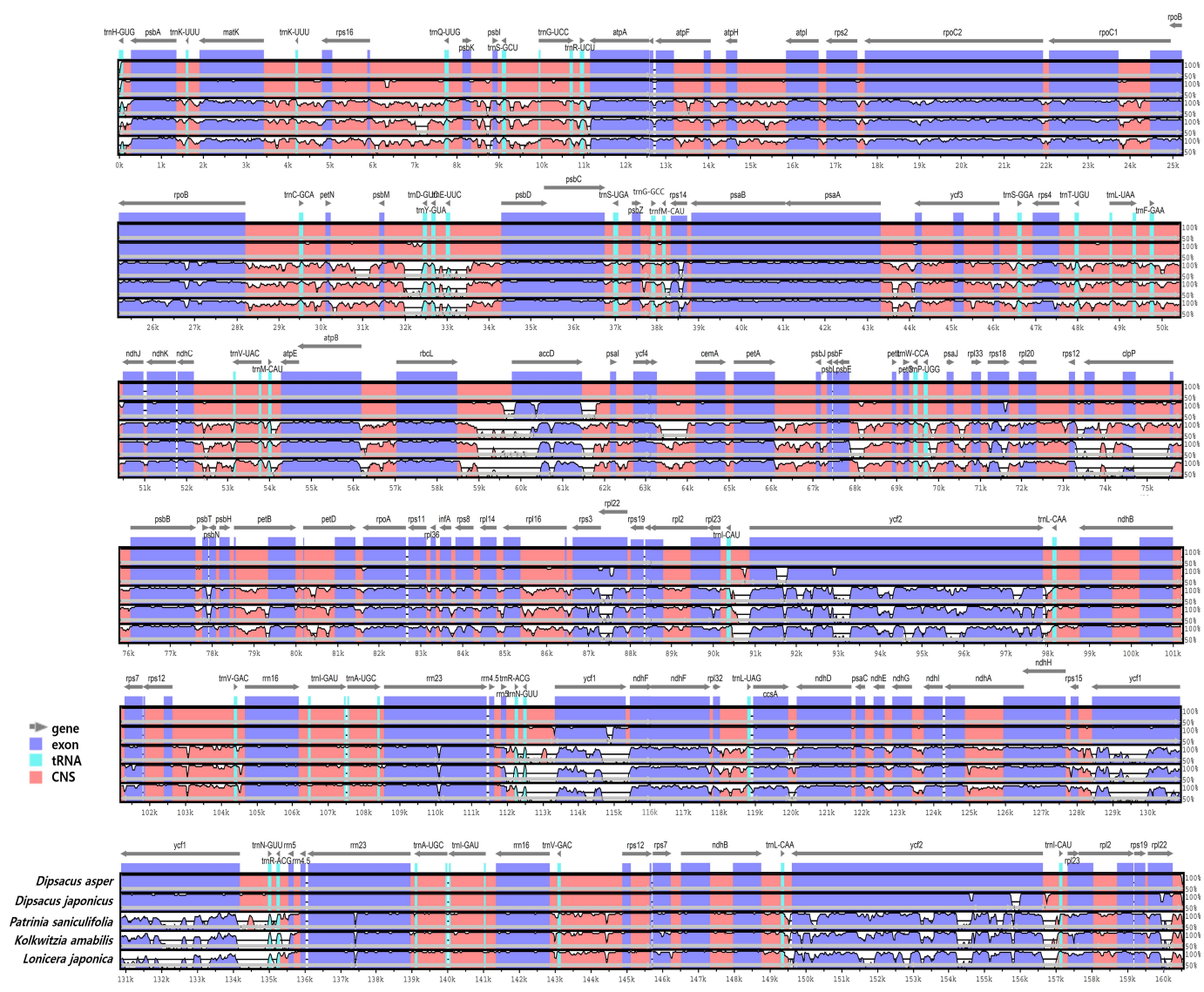

Figure 2. The comparative analysis of chloroplast genomes of species within the family Caprifoliaceae using mVISTA. Blue indicates conserved genes, light blue indicates tRNA and rRNA, red indicates conserved non-coding sequences (CNS), and white represents divergent regions. A cut-off of a $50 \%$ identity was used for the plots. The $Y$-axis represents $50-100 \%$ identity.

The ratio of non-synonymous to synonymous mutation rates $(\mathrm{Ka} / \mathrm{Ks})$ was used to understand gene evolution. Adaptive evolution in response to the environment occurs when the genes are under positive selection $[37,44,45]$. We calculated the $\mathrm{Ka} / \mathrm{Ks}$ ratios of 78 collinear protein-coding genes in the two Dipsacus species against those in L. japonica to identify the selection pressure on these genes in Caprifoliaceae (Figure 3). The most conserved genes appeared to be undergoing purifying selection, as the $\mathrm{Ka} / \mathrm{Ks}$ ratio was less than 0.001 . No significant differences were detected in the $\mathrm{Ka} / \mathrm{Ks}$ ratios among the LSC, IR, and SSC regions. The Ka/Ks ratios of the two Dipsacus species varied from 0.001 to 1.843 (average $=0.284$ ). The $\mathrm{Ka} / \mathrm{Ks}$ ratio of the rps genes encoding the small ribosomal subunits was 0.524 , indicating a relaxed selection. Among the rps genes, rps7 showed the highest Ka/Ks ratio (1.843), indicating a positive selection. The rps7 gene encodes the ribosomal protein $\mathrm{S} 7$ and has been reported under a positive selection in the Salix species (Salicaceae). The $\operatorname{lpP}$ and $y c f 2$ genes also showed positive selection $(\mathrm{Ka} / \mathrm{Ks}>1)$; these genes have been frequently reported as lost or highly variable $[6,10,46]$. The $c l p P$ gene encodes a protein involved in translation and protein modification, whereas $y c f 2$ has an unknown function [6]. In this study, $c l p P$ and $y c f 2$ showed a weak selection during the adaptive evolution in Caprifoliaceae. Taken together, we suggest that $r p s 7, y c f 2$, and $c l p P$ evolved rapidly in Caprifoliaceae. These genes were found from other CP genomes [47,48]. We propose that the positive selection of these genes undergo essential adaptations to the environment.

To examine divergence at the sequence level in D. asper and D. japonicus, we estimated the Pi (Figure 4). A total of 81 regions with a Pi value greater than zero were classified as coding, non-coding, and IGS. Single copy regions (LSC and SSC) were more variable than the IR regions. The average $\mathrm{Pi}$ values for the single copy regions was 000054 and 0.0065 for the IR regions. Genic regions were 
more conserved than the IGS region. The ycf2-trnL region showed the highest Pi value of 0.0325 . Among the protein-coding genes, $c l p P$ showed the highest $P i$ value and was highly variable in the two Dipsacus species, indicating the positive selection in Caprifoliaceae. Although the $\mathrm{CP}$ genomes of $D$. asper and $D$. japonicus showed a highly conserved structure, the intergenic regions and a few coding regions diverged. In the chloroplast genomes of angiosperms, the intergenic regions have a higher representation than the genic regions [49].
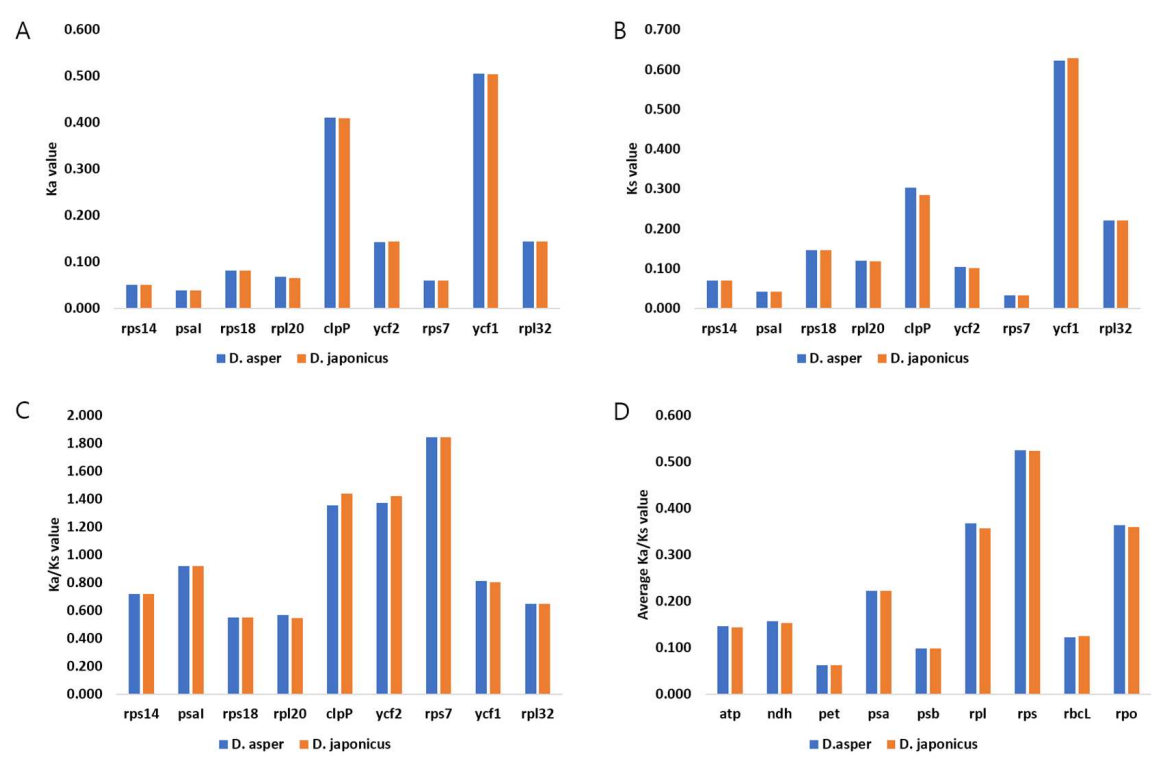

Figure 3. The analysis of $\mathrm{Ka}, \mathrm{Ks}$, and $\mathrm{Ka} / \mathrm{Ks}$ values of the chloroplast genomes of D. asper, D. japonicus, and L. japonica. The ratio of non-synonymous substitution rate $(\mathrm{Ka})$ to synonymous substitution rate (Ks) was calculated for 78 conserved protein-coding genes. (A) Ka values of genes with $\mathrm{Ka} / \mathrm{Ks}>0.5$. (B) Ks value of genes with $\mathrm{Ka} / \mathrm{Ks}>0.5$. (C) Ka/Ks values of specific genes. (D) Average Ka/Ks values of gene groups.

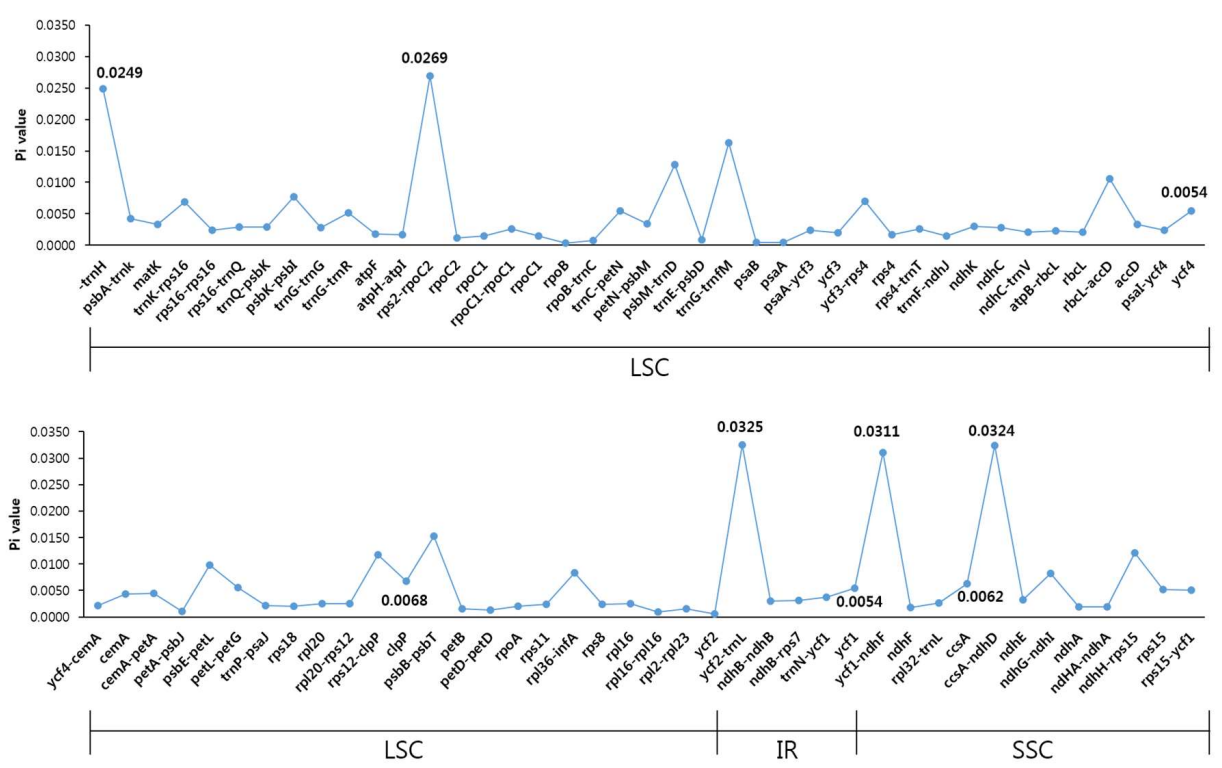

Figure 4. The comparison of nucleotide diversity (Pi) between the chloroplast genomes of D. asper and D. japonicus. 
The $\mathrm{CP}$ genomes have been successfully used in numerous phylogenetic studies of angiosperms. Using the chloroplast genomes is advantageous, as these are more accurate and have a greater resolution than a few cp loci and nuclear rDNA ITS regions [50,51]. We investigated the phylogenetic relationship among 18 species in the families Caprifoliaceae and Adoxaceae within the order Dipsacales, and in the family Araliaceae within the order Apiales using the maximum likelihood (ML) and Bayesian inference (BI). Sequences of $69 \mathrm{CP}$ protein-coding genes from all 18 species were aligned (alignment length $=58,243 \mathrm{bp}$ ) (Figure 5). Most nodes showed 100\% ML bootstrap values and 1.0 BI posterior probabilities, except for two nodes in Araliaceae. All 18 species have been shown to cluster according to the APG IV system [52]. P. saniculifolia formed a sister group with two Dipsacus species, and. L. japonica showed a distinct phylogenetic relationship to the other four species in Caprifoliaceae. The phylogenic tree reconstructed in this study was clearly consistent with those in previous studies [53-55]. Previous studies used the ITS/ITS2 region or other CP loci to understand the phylogenetic relationship among the Caprifoliaceae or Dipsacales species [53-55]. Despite the few CP genomes applied in this study, this is the first report of phylogenetic analysis of the genus Dipsacus using protein-coding genes in the $\mathrm{CP}$ genome. These data provide an improved phylogenetic relationship among the species within Caprifoliaceae, supported by strong bootstrap values.

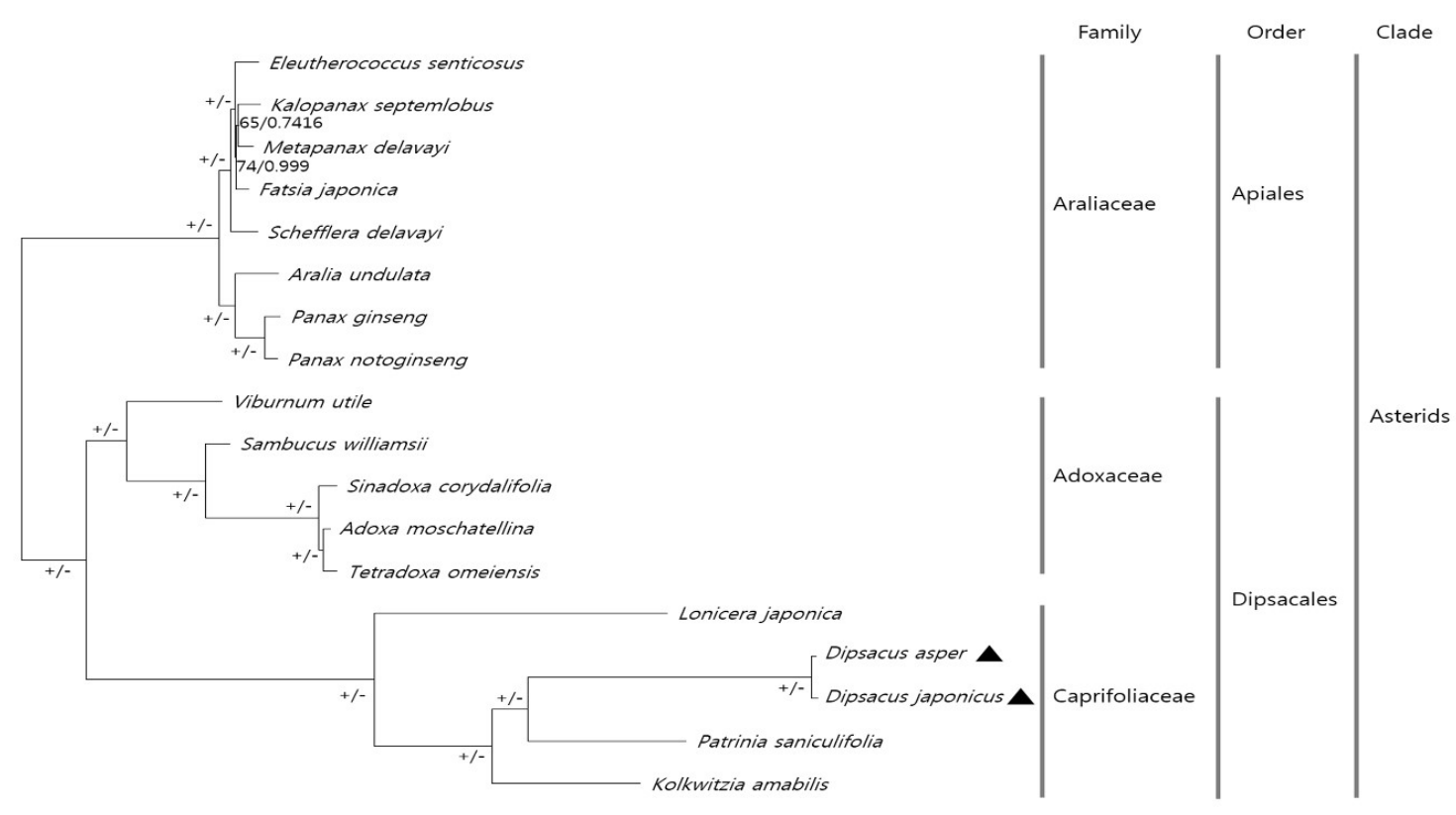

Figure 5. The phylogenetic analysis of 69 protein-coding genes in 18 species, including D. asper and D. japonicus, using the maximum likelihood (ML) method and Bayesian posterior probabilities (PP). The ML topology is shown with the ML bootstrap support values and Bayesian PP given at each node. A total of $100 \%$ bootstrap and 1.0 PP support are indicated above each node using + and - , respectively. The black triangles indicate the CP genomes of D. asper and D. japonicus examined in this study.

\subsection{Authentication of D. asper, D. japonicus, and P. umbrosa Using SCAR Markers}

The gene region is more stable than the IGS region for the development of molecular markers. In this study, indels were detected in the $a c c D$ gene of both Dipsacus species and in the matK gene of P. umbrosa. We used these indels for the development of SCAR markers to distinguish between D. asper and D. japonicus. The primer pairs DAJ-AC_F/DAJ-AC_R and PU-M_F/PU-M_R were used to amplify the $a c c D$ and $m a t K$ genes from the two Dipsacus species and P. umbrosa, respectively (Table S9). We also tested these markers on 12 individual plants, including five $D$. asper, three $D$. japonicus, and four P. umbrosa individual plants, obtained from the Korea Institute of Oriental Medicine (KIOM) (Figure 6 and Table S10). The DAJ-AC primers amplified 185 and $329 \mathrm{bp}$ amplicons from D. asper and D. japonicus, 
respectively, but showed no amplification from $P$. umbrosa. In contrast, the PU-M primers amplified a 256 bp fragment from $P$. umbrosa but not from the Dipsacus species.

A

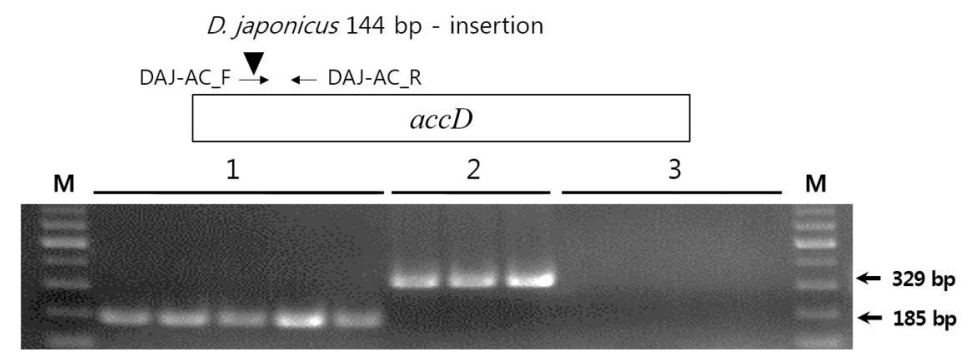

B

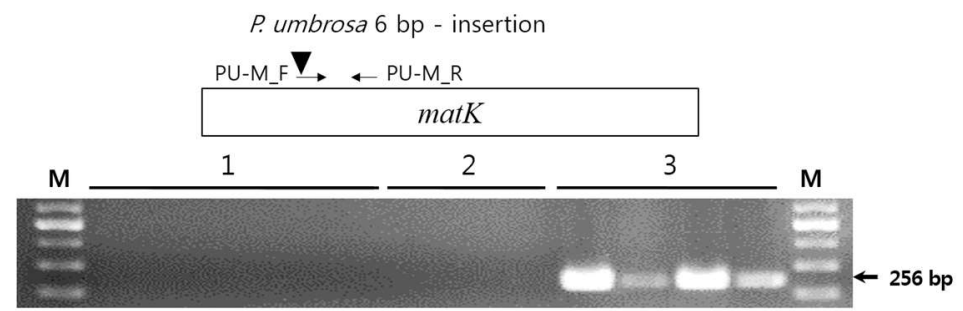

Figure 6. The gel images of CP DNA of D. asper, D. japonicus, and P. umbrosa amplified using sequence characterised amplified region (SCAR) markers. Twelve individual plants were used in this study using (A) DAJ-AC and (B) PU-M primers. Details of the germplasm are provided in Supplementary Table S10. (1) D. asper, (2) D. japonicus, (3) P. umbrosa.

SCAR markers are a valuable tool for species identification and have been used to discriminate herbal medicines from adulterants. Moreover, SCAR markers are reliable and easy to use, requiring only PCR and gel electrophoresis [18]. A CP-specific SCAR marker was previously used to distinguish Aconitum coreanum from its closely related species on the basis of a 6 bp insertion in its CP genome [16]. The nuclear rDNA ITS barcode region has been frequently used for the development of SCAR markers as it is highly variable in sequence. SCAR markers have been used to differentiate valuable herbal plants, including Aralia continentalis and Angelica biserrata, from adulterants [17]. Therefore, SCAR markers are a powerful molecular tool for the identification of herbal medicines. The novel SCAR markers developed in this study will be useful for the identification of D. asper, D. japonicus, and P. umbrosa and the authentication of herbal medicines.

\section{Materials and Methods}

\subsection{Plant Materials}

Fresh leaves of D. asper $\left(36^{\circ} 43^{\prime} 35.9^{\prime \prime} \mathrm{N}\right.$ and $\left.127^{\circ} 27^{\prime} 38.0^{\prime \prime} \mathrm{E}\right)$ and D. japonicus $\left(37^{\circ} 14^{\prime} 04.5^{\prime \prime} \mathrm{N}\right.$ and $\left.128^{\circ} 56^{\prime} 57.0^{\prime \prime} \mathrm{E}\right)$ were collected from their native habitats in Korea. All samples were assigned unique identification numbers and registered with the Korean Herbarium of Standard Herbal Resources (Index Herbarium code KIOM) at the KIOM. Details of these samples are listed in the Supplementary Table S10.

\subsection{Universal DNA Barcode Analysis for D. asper, D. japonicus, and P. umbrosa}

Universal DNA barcodes, including ITS2, mat $K$, and $r b c L$, were PCR amplified using ITS2-s2f/ITS4, matK-AF/matK-8R, and rbcL-N/rbcL-R primer pairs, respectively, from the nuclear and CP of D. asper, D. japonicus, and P. umbrosa, using previously described amplification parameters [56-58]. The amplified DNA fragments were extracted from the agarose gel using a gel extraction kit, cloned into a pGEM-T Easy vector (Promega, Madison, WI, USA), and sequenced on an ABI 3730 DNA Analyzer (Applied Biosystems Inc., Foster City, CA, USA) [17,18]. The obtained sequences were 
aligned and edited using BioEdit ver. 7.2.5 [59]. Parsimony informative sites and Pi values were calculated using DnaSP ver. 5.1 [60].

\subsection{Genome Sequencing and Assembly}

DNA was extracted using DNeasy Plant Maxi kit (Qiagen, Valencia, CA, USA), according to the manufacturer's instructions. Illumina short-insert paired-end sequencing libraries were constructed and sequenced using the NextSeq platform (Illumina, San Diego, CA, USA). CP genome sequences were determined from the de novo assembly of low-coverage whole-genome sequences. Trimmed paired-end reads (Phred score $\geq 20$ ) were assembled using the CLC genome assembler ver. 4.06 beta (CLC Inc., Rarhus, Denmark) with the default parameters. Principal contigs representing the chloroplast genome were retrieved from the total collection of contigs using Nucmer [61] and aligned with the chloroplast genome sequence of Ilex wilsonii (KX426471) as a reference. A de novo SOAP gap closer was performed to fill the gaps based on aligned paired-end reads [62]. PCR-based sequencing was used to validate the sequences of the four chloroplast junction regions, LSC/IR, IR/SSC, SSC/IR, and IR/LSC, using the primers listed in Supplementary Table S2. Finally, the CP genome sequence reads were mapped onto the complete genomes using a Burrows-Wheel Aligner ver. 0.7.25 [63].

\subsection{Genome Annotation and Comparative Analysis}

Gene annotation of the CP genomes of D. asper and D. japonicus was performed using GeSeq [64] and the annotation results were concatenated using an in-house pipeline. Protein-coding sequences were manually curated and confirmed using Artemis [65] and checked against the protein database of the National Center for Biotechnology Information (NCBI). Sequences of the tRNA genes were confirmed using tRNAscan-SE 1.21 [66], and those of the IR regions were confirmed using the IR finder and RepEx [67]. Circular maps of the two Dipsacus CP genomes were obtained using OGDRAW [68]. The GC content and RSCU values were analysed using the MEGA6 software [69]. Sequences of the LSC/IR, IR/SSC, SSC/IR, and IR/LSC junctions of the completed CP genomes were validated via PCR-based sequencing using the primers listed in Tables S2 and S3. NCBI accession numbers of the $\mathrm{CP}$ genome sequences of $D$. asper and D. japonicus are MH074864 and MH074865, respectively. The CP genomes of D. asper, D. japonicus, Patrinia saniculifolia (NC_036835.1), Kolkwitzia amabilis (NC_029874.1), and Lonicera japonica (NC_026839.1) were compared using mVISTA in the Shuffle-LAGAN mode, with the $C P$ genome of $D$. asper as a reference. The Pi values for $D$. asper and $D$. japonicus were calculated using DnaSP ver. 5.1 [60]. The step size was set to $200 \mathrm{bp}$. To analyse the synonymous (Ks) and non-synonymous substitution rates, shared functional protein gene sequences and amino acid sequences were used for calculating Ka and Ks values using PAML with the yn00 program [70].

\subsection{Repeat Analysis}

SSRs in the CP genomes of the two Dipsacus species were detected using MISA [71], with the minimum number of repeats set to 10, 5, 4, 3, 3, and 3 for mono-, di-, tri-, tetra-, penta-, and hexa-nucleotides, respectively. The minimum alignment score and maximum period size of tandem and palindromic repeats for 20 or more bp were set at 50 and 500, respectively, and the identity of repeats was set to $90 \%$ or greater $[72,73]$.

\subsection{Phylogenetic Analysis}

The CP genomes of 18 species belonging to the families Caprifoliaceae, Adoxaceae, and Araliaceae were subjected to phylogenetic analyses. Of these, the $\mathrm{CP}$ genome sequences of 16 species were downloaded from NCBI (Supplementary Table S11). To construct the phylogenetic tree, sequences of 69 protein-coding genes were aligned using MAFFT [74] and manually adjusted using BioEdit [59]. The best-fitting model of nucleotide substitutions was determined according to the Akaike Information Criterion (AIC) in JModeltest ver. 2.1.10 [75]. The GTR+I+G model was used in both. The maximum likelihood method was used to construct the phylogenetic tree in MEGA6 [69], with 1000 bootstrap 
replicates. Bayesian inference analyses were conducted using MrBayes ver. 3.2.2 [76], with two independent runs and four chains using the Markov chain Monte Carlo (MCMC), and simultaneous runs for one million generations. Each chain started with a random tree with default priors. Phylogenetic trees were sampled every 1,000,000 generations with the first 25\% discarded as burn-in. The consensus tree was determined based on the $50 \%$ majority rule to estimate the posterior probabilities.

\subsection{Development of SCAR Markers for D. asper, D. japonicus, and P. umbrosa}

To develop the SCAR markers, primers flanking the variable region in the accD gene of $D$. asper and D. japonicus were designed using the Primer-BLAST (NCBI) [77]. The genomic DNA (20 ng) of D. asper, D. japonicus, and P. umbrosa was PCR amplified in a $20 \mathrm{~L}$ volume using 10 pmol primers. SCAR markers were amplified using species-specific primers (DAJ-AC and PU-M, Table S9), according to the following conditions: DAJ-AC, $95^{\circ} \mathrm{C}$ for $2 \mathrm{~min}$, followed by 35 cycles at $95{ }^{\circ} \mathrm{C}$ for $30 \mathrm{~s}, 63^{\circ} \mathrm{C}$ for $30 \mathrm{~s}$, and $72{ }^{\circ} \mathrm{C}$ for $30 \mathrm{~s}$, and a final extension at $72{ }^{\circ} \mathrm{C}$ for $5 \mathrm{~min}$; PU-M, $95{ }^{\circ} \mathrm{C}$ for $2 \mathrm{~min}$, followed by 35 cycles at $95{ }^{\circ} \mathrm{C}$ for $50 \mathrm{~s}, 63^{\circ} \mathrm{C}$ for $30 \mathrm{~s}$, and $72{ }^{\circ} \mathrm{C}$ for $50 \mathrm{~s}$, and a final extension at $72{ }^{\circ} \mathrm{C}$ for $5 \mathrm{~min}$. The PCR products were verified by gel electrophoresis on a $2 \%$ agarose gel for $40 \mathrm{~min}$ at $150 \mathrm{~V}$.

\section{Conclusions}

In this study, we performed a DNA barcoding analysis of D. asper, D. japonicus and P. umbrosa which are important herbal plants. We sequenced the chloroplast genomes of D. asper, D. japonicus. D. asper and D. japonicus, which exhibited slightly different parsimony informative sites in the ITS2, matK, and $r b c L$ regions. The CP genome structure of these two Dipsacus species was highly conserved but was different from that of the other Caprifoliaceae species. We also investigated the phylogenetic relationship among the Caprifoliaceae species; this is the first report of phylogenetic analysis of the two Dipsacus species based on CP genomes. Additionally, we developed novel SCAR markers, DAJ-AC and PU-M, for the identification of the authentic herbal medicines, Dipsaci Radix and Phlomidis Radix. Taken together, these data facilitate the distinguishing of D. asper, D. japonicus, and P. umbrosa from adulterants in the herbal medicine market and enable the commercial use of the Dipsaci Radix and Phlomidis Radix. Furthermore, these results provide valuable information on the CP genomes and evolution of species within Caprifoliaceae.

Supplementary Materials: The following are available online. Figure S1: Distribution of paired-end reads mapped onto the complete chloroplast genomes of Dipsacus asper and D. japonicus, Figure S2: Frequencies of amino acid in two Dipsacus protein-coding sequences, Figure S3: Relative synonymous codon usage (RSCU) values for 20 amino acids and the stop codon in 78 protein-coding genes present in the chloroplast genomes of D. asper and D. japonicus, Figure S4: Distribution of simple sequence repeats (SSRs) in the chloroplast genomes of D. asper and D. japonicus. Number of (A) SSRs in exons, introns, and intergenic spacer (IGS) regions; (B) different SSR types; (C) SSRs per unit length of the chloroplast genomes; and (D) common and species-specific SSRs, Figure S5: Analysis of tandem repeats in the chloroplast genomes of D. asper and D. japonicus. Distribution of (A) tandem repeats of different lengths and (B) tandem repeats in different regions of the chloroplast genomes. Number of (C) tandem repeats in the IGS region, exons, and introns; and (D) common and species-specific tandem repeats, Figure S6: Comparison of junctions between the large single copy (LSC) region, inverted repeat (IR) regions (IRa and IRb), and small single copy (SSC) region in the chloroplast genomes of the Caprifoliaceae species, Dipsacus asper, Dipsacus japonicus, Patrinia saniculifolia, Kolkwitzia amabilis, and Lonicera japonica, Table S1: Details of the raw sequence reads and chloroplast genome assembly of the two Dipsacus species, Table S2: List of primers used for the validation of chloroplast genomes of D. asper and D. japonicus, Table S3: Polymerase chain reaction (PCR)-based sequence validation of junctions between the large single copy (LSC), small single copy (SSC), and inverted repeat (IRa and IRb) regions in the chloroplast genomes of D. asper and D. japonicus, Table S4: List of genes identified in the chloroplast genomes of $D$. asper and D. japonicus along with the encoded proteins, Table S5: Location and sizes of genes in the chloroplast genomes of D. asper and D. japonicus, Table S6: Distribution of amino acids in the chloroplast genomes of D. asper and D. japonicus, Table S7: Details of polymorphic simple sequence repeats (SSRs) in the chloroplast genomes of D. asper and D. japonicus, Table S8: Details of palindromic repeats in the chloroplast genomes of D. asper and D. japonicus, Table S9: List of primers used for the amplification of sequence characterised amplified region (SCAR) markers, Table S10: Details of germplasm used in this study, Table S11: List of chloroplast genomes downloaded from National Center for Biotechnology Information (NCBI) for phylogenetic analysis. 
Author Contributions: Experimental design, I.P.; collection and identification of plant material, S.Y. and B.C.M.; experiment execution, W.J.K. and P.N.; chloroplast genome analysis, I.P. and H.O.L.; manuscript draft preparation, I.P.; manuscript review, I.P. and B.C.M. All authors contributed to the experiments and approved the final manuscript.

Funding: This work was supported by a grant of the Development of Foundational Techniques for the Domestic Production of Authentic Herbal Medicines, based on the Establishment of Molecular Authentication System (K17403 and K18403) from the Korea Institute of Oriental Medicine (KIOM). The grant was funded by the Ministry of Science and ICT (MSIT) of the Republic of Korea.

Acknowledgments: The authors would like to thank the "Classification and Identification Committee of the KIOM" for the identification of plant materials and the Herbarium of Korea Standard Herbal Resources (Index Herbariorum code KIOM) for the provision of plant materials.

Conflicts of Interest: The authors declare no conflicts of interest.

\section{References}

1. Ali, M.A.; Gyulai, G.; Al-Hermaid, F. Plant DNA Barcoding and Phyogenetics; LAP LAMBERT Academic Publishing: Saarbrücken, Germany, 2015; pp. 109-130.

2. Li, X.; Yang, Y.; Henry, R.J.; Rossetto, M.; Wang, Y.; Chen, S. Plant DNA barcoding: From gene to genome. Biol. Rev. Camb. Philos. Soc. 2015, 90, 157-166. [CrossRef] [PubMed]

3. Kress, W.J.; Wurdack, K.J.; Zimmer, E.A.; Weigt, L.A.; Janzen, D.H. Use of DNA barcodes to identify flowering plants. Proc. Natl. Acad. Sci. USA 2005, 102, 8369-8374. [CrossRef] [PubMed]

4. Austerlitz, F.; David, O.; Schaeffer, B.; Bleakley, K.; Olteanu, M.; Leblois, R.; Veuille, M.; Laredo, C. DNA barcode analysis: A comparison of phylogenetic and statistical classification methods. BMC Bioinform. 2009, 10 (Suppl. 14), S10. [CrossRef] [PubMed]

5. Mishra, P.; Kumar, A.; Nagireddy, A.; Mani, D.N.; Shukla, A.K.; Tiwari, R.; Sundaresan, V. DNA barcoding: An efficient tool to overcome authentication challenges in the herbal market. Plant Biotechnol. J. 2016, 14, 8-21. [CrossRef] [PubMed]

6. Wicke, S.; Schneeweiss, G.M.; dePamphilis, C.W.; Muller, K.F.; Quandt, D. The evolution of the plastid chromosome in land plants: Gene content, gene order, gene function. Plant Mol. Biol. 2011, 76, $273-297$. [CrossRef] [PubMed]

7. Delannoy, E.; Fujii, S.; Colas des Francs-Small, C.; Brundrett, M.; Small, I. Rampant gene loss in the underground orchid Rhizanthella gardneri highlights evolutionary constraints on plastid genomes. Mol. Biol. Evol. 2011, 28, 2077-2086. [CrossRef] [PubMed]

8. Stegemann, S.; Keuthe, M.; Greiner, S.; Bock, R. Horizontal transfer of chloroplast genomes between plant species. Proc. Natl. Acad. Sci. USA 2012, 109, 2434-2438. [CrossRef] [PubMed]

9. Jansen, R.K.; Ruhlman, T.A. Plastid genomes of seed plants. In Genomics of Chloroplasts and Mitochondria; Springer: Dordrecht, The Netherlands, 2012; pp. 103-126.

10. Daniell, H.; Lin, C.S.; Yu, M.; Chang, W.J. Chloroplast genomes: Diversity, evolution, and applications in genetic engineering. Genome Biol. 2016, 17, 134. [CrossRef] [PubMed]

11. Kim, K.; Lee, S.C.; Lee, J.; Lee, H.O.; Joh, H.J.; Kim, N.H.; Park, H.S.; Yang, T.J. Comprehensive survey of genetic diversity in chloroplast genomes and $45 \mathrm{~S}$ nrDNAs within Panax ginseng species. PLoS ONE 2015, 10, e0117159. [CrossRef] [PubMed]

12. Parks, M.; Cronn, R.; Liston, A. Increasing phylogenetic resolution at low taxonomic levels using massively parallel sequencing of chloroplast genomes. BMC Biol. 2009, 7, 84. [CrossRef] [PubMed]

13. Cho, K.S.; Yun, B.K.; Yoon, Y.H.; Hong, S.Y.; Mekapogu, M.; Kim, K.H.; Yang, T.J. Complete chloroplast genome sequence of tartary buckwheat (Fagopyrum tataricum) and comparative analysis with common buckwheat (F. esculentum). PLoS ONE 2015, 10, e0125332. [CrossRef] [PubMed]

14. Hong, S.Y.; Cheon, K.S.; Yoo, K.O.; Lee, H.O.; Cho, K.S.; Suh, J.T.; Kim, S.J.; Nam, J.H.; Sohn, H.B.; Kim, Y.H. Complete chloroplast genome sequences and comparative analysis of Chenopodium quinoa and C. album. Front. Plant Sci. 2017, 8, 1696. [CrossRef] [PubMed]

15. Bhagyawant, S.S. Rapd-SCAR markers: An interface tool for authentication of traits. J. Biosci. Med. 2016, 4, 1-9. [CrossRef] 
16. Park, I.; Kim, W.J.; Yang, S.; Yeo, S.M.; Li, H.; Moon, B.C. The complete chloroplast genome sequence of Aconitum coreanum and Aconitum carmichaelii and comparative analysis with other Aconitum species. PLoS ONE 2017, 12, e0184257. [CrossRef] [PubMed]

17. Kim, W.J.; Moon, B.C.; Yang, S.; Han, K.S.; Choi, G.; Lee, A.Y. Rapid authentication of the herbal medicine plant species Aralia continentalis kitag. and Angelica biserrata C.Q. Yuan and R.H. Shan using ITS2 sequences and multiplex-SCAR markers. Molecules 2016, 21, 270. [CrossRef] [PubMed]

18. Moon, B.C.; Kim, W.J.; Han, K.S.; Yang, S.; Kang, Y.; Park, I.; Piao, R. Differentiating authentic Adenophorae radix from its adulterants in commercially-processed samples using multiplexed its sequence-based SCAR markers. Appl. Sci. 2017, 7, 660. [CrossRef]

19. Park, I.; Kim, J.; Lee, J.; Kim, S.; Cho, O.; Yang, K.; Ahn, J.; Nahm, S.; Kim, H. Development of SSR markers by next-generation sequencing of Korean landraces of chamoe (Cucumis melo var. Makuwa). Mol. Biol. Rep. 2013, 40, 6855-6862. [CrossRef] [PubMed]

20. Zalapa, J.E.; Cuevas, H.; Zhu, H.; Steffan, S.; Senalik, D.; Zeldin, E.; McCown, B.; Harbut, R.; Simon, P. Using next-generation sequencing approaches to isolate simple sequence repeat (SSR) loci in the plant sciences. Am. J. Bot. 2012, 99, 193-208. [CrossRef] [PubMed]

21. Qian, J.; Song, J.; Gao, H.; Zhu, Y.; Xu, J.; Pang, X.; Yao, H.; Sun, C.; Li, X.; Li, C.; et al. The complete chloroplast genome sequence of the medicinal plant Salvia miltiorrhiza. PLoS ONE 2013, 8, e57607. [CrossRef] [PubMed]

22. Park, I.; Kim, W.J.; Yeo, S.-M.; Choi, G.; Kang, Y.-M.; Piao, R.; Moon, B.C. The complete chloroplast genome sequences of Fritillaria ussuriensis Maxim. and Fritillaria cirrhosa D. Don, and comparative analysis with other Fritillaria species. Molecules 2017, 22, 982. [CrossRef] [PubMed]

23. Korea Institute of Oriental Medicine (KIOM). Defining Dictionary for Medicinal Herbs. 2018. Available online: http:/ / boncho.kiom.re.kr/codex/ (accessed on 2 May 2018).

24. Moon, B.C.; Choi, G.; Yuan, Y. Origins of herbal medicines and adulterants in Korea and china. Korea Inst. Orient. Med. 2017, 1, 117.

25. Ministry of Food and Drug safety (M.F.D). Korean Food Standard Codex 2010; Ministry of Food and Drug Safety: Cheongju, Korea, 2010.

26. Wong, R.W.; Rabie, A.B.; Hagg, E.U. The effect of crude extract from radix Dipsaci on bone in mice. Phytother. Res. 2007, 21, 596-598. [CrossRef] [PubMed]

27. Song, J.S.; Lim, K.M.; Kang, S.; Noh, J.Y.; Kim, K.; Bae, O.N.; Chung, J.H. Procoagulant and prothrombotic effects of the herbal medicine, Dipsacus asper and its active ingredient, dipsacus saponin C, on human platelets. J. Thromb. Haemost. 2012, 10, 895-906. [CrossRef] [PubMed]

28. Shang, X.; Wang, J.; Li, M.; Miao, X.; Pan, H.; Yang, Y.; Wang, Y. Antinociceptive and anti-inflammatory activities of Phlomis umbrosa Turcz extract. Fitoterapia 2011, 82, 716-721. [CrossRef] [PubMed]

29. Shin, T.Y.; Kim, S.H.; Kim, D.K.; Leem, K.H.; Park, J.S. Phlomis umbrosa root inhibits mast cell-dependent allergic reactions and inflammatory cytokine secretion. Phytother. Res. 2008, 22, 153-158. [CrossRef] [PubMed]

30. Stevens, P.F.; Davis, H. Angiosperm Phylogeny Website. 2001. Available online: http://www.mobot.org/ MOBOT/research/APweb/ (accessed on 18 May 2018).

31. Deyuan, H.; Liming, M.; Fred, R.B. Dipsacus L. In Flora of China; Wu, Z.Y., Raven, P.H., Eds.; Science Press: Beijing, China; Missouri Botanical Garden Press: St. Louis, MO, USA, 2011; Volume 19, pp. 658-660.

32. Dahui, L.; Zaigui, W.; Xueshi, L.; Yi, Y. Identification of the medicinal plant Dipsacus asperoides from three other species in genus Dipsacus (Dipsaceae) by internal transcribed spacer of ribosomal deoxyribonucleic acid (rDNA ITS). J. Med. Plant Res. 2012, 6, 289-295. [CrossRef]

33. Sasaki, T.; Yukawa, Y.; Miyamoto, T.; Obokata, J.; Sugiura, M. Identification of RNA editing sites in chloroplast transcripts from the maternal and paternal progenitors of tobacco (Nicotiana tabacum): Comparative analysis shows the involvement of distinct trans-factors for $n d h B$ editing. Mol. Biol. Evol. 2003, 20, 1028-1035. [CrossRef] [PubMed]

34. Kahlau, S.; Aspinall, S.; Gray, J.C.; Bock, R. Sequence of the tomato chloroplast DNA and evolutionary comparison of Solanaceous plastid genomes. J. Mol. Evol. 2006, 63, 194-207. [CrossRef] [PubMed]

35. Gao, L.; Yi, X.; Yang, Y.X.; Su, Y.J.; Wang, T. Complete chloroplast genome sequence of a tree fern Alsophila spinulosa: Insights into evolutionary changes in fern chloroplast genomes. BMC Evol. Biol. 2009, 9, 130. [CrossRef] [PubMed] 
36. Wang, Y.; Zhan, D.F.; Jia, X.; Mei, W.L.; Dai, H.F.; Chen, X.T.; Peng, S.Q. Complete chloroplast genome sequence of Aquilaria sinensis (lour.) gilg and evolution analysis within the Malvales order. Front. Plant Sci. 2016, 7, 280. [PubMed]

37. Ivanova, Z.; Sablok, G.; Daskalova, E.; Zahmanova, G.; Apostolova, E.; Yahubyan, G.; Baev, V. Chloroplast genome analysis of resurrection tertiary relict Haberlea rhodopensis highlights genes important for desiccation stress response. Front. Plant Sci. 2017, 8, 204. [CrossRef] [PubMed]

38. Asaf, S.; Khan, A.L.; Khan, A.R.; Waqas, M.; Kang, S.M.; Khan, M.A.; Lee, S.M.; Lee, I.J. Complete chloroplast genome of Nicotiana otophora and its comparison with related species. Front. Plant Sci. 2016, 7, 843. [CrossRef] [PubMed]

39. Zhou, J.; Cui, Y.; Chen, X.; Li, Y.; Xu, Z.; Duan, B.; Li, Y.; Song, J.; Yao, H. Complete chloroplast genomes of Papaver rhoeas and Papaver orientale: Molecular structures, comparative analysis, and phylogenetic analysis. Molecules 2018, 23, 437. [CrossRef] [PubMed]

40. Huang, Y.Y.; Matzke, A.J.; Matzke, M. Complete sequence and comparative analysis of the chloroplast genome of coconut palm (Cocos nucifera). PLoS ONE 2013, 8, e74736. [CrossRef] [PubMed]

41. Raubeson, L.A.; Peery, R.; Chumley, T.W.; Dziubek, C.; Fourcade, H.M.; Boore, J.L.; Jansen, R.K. Comparative chloroplast genomics: Analyses including new sequences from the angiosperms Nuphar advena and Ranunculus macranthus. BMC Genom. 2007, 8, 174. [CrossRef] [PubMed]

42. Nie, X.; Lv, S.; Zhang, Y.; Du, X.; Wang, L.; Biradar, S.S.; Tan, X.; Wan, F.; Weining, S. Complete chloroplast genome sequence of a major invasive species, crofton weed (Ageratina adenophora). PLoS ONE 2012, 7, e36869. [CrossRef] [PubMed]

43. Khakhlova, O.; Bock, R. Elimination of deleterious mutations in plastid genomes by gene conversion. Plant J. 2006, 46, 85-94. [CrossRef] [PubMed]

44. Kimura, M. The neutral theory of molecular evolution and the world view of the neutralists. Genome 1989, 31, 24-31. [CrossRef] [PubMed]

45. Raman, G.; Park, S. The complete chloroplast genome sequence of ampelopsis: Gene organization, comparative analysis, and phylogenetic relationships to other angiosperms. Front. Plant Sci. 2016, 7, 341. [CrossRef] [PubMed]

46. Rockenbach, K.; Havird, J.C.; Monroe, J.G.; Triant, D.A.; Taylor, D.R.; Sloan, D.B. Positive selection in rapidly evolving plastid-nuclear enzyme complexes. Genetics 2016, 204, 1507-1522. [CrossRef] [PubMed]

47. Redwan, R.M.; Saidin, A.; Kumar, S.V. Complete chloroplast genome sequence of MD-2 pineapple and its comparative analysis among nine other plants from the subclass Commelinidae. BMC Plant Biol. 2015, 15, 196. [CrossRef] [PubMed]

48. Wu, M.; Li, Q.; Hu, Z.; Li, X.; Chen, S. The complete Amomum kravanh chloroplast genome sequence and phylogenetic analysis of the Commelinids. Molecules 2017, 22, 1875.

49. Park, I.; Yang, S.; Choi, G.; Kim, W.J.; Moon, B.C. The complete chloroplast genome sequences of Aconitum pseudolaeve and Aconitum longecassidatum, and development of molecular markers for distinguishing species in the Aconitum subgenus Lycoctonum. Molecules 2017, 22, 2012. [CrossRef] [PubMed]

50. Jansen, R.K.; Cai, Z.; Raubeson, L.A.; Daniell, H.; Leebens-Mack, J.; Müller, K.F.; Guisinger-Bellian, M.; Haberle, R.C.; Hansen, A.K.; Chumley, T.W. Analysis of 81 genes from 64 plastid genomes resolves relationships in angiosperms and identifies genome-scale evolutionary patterns. Proc. Natl. Acad. Sci. USA 2007, 104, 19369-19374. [CrossRef] [PubMed]

51. Moore, M.J.; Bell, C.D.; Soltis, P.S.; Soltis, D.E. Using plastid genome-scale data to resolve enigmatic relationships among basal angiosperms. Proc. Natl. Acad. Sci. USA 2007, 104, 19363-19368. [CrossRef] [PubMed]

52. The Angiosperm Phylogeny Group. An update of the Angiosperm Phylogeny Group classification for the orders and families of flowering plants: APG IV. Bot. J. Linn. Soc. 2016, 181, 1-20. [CrossRef]

53. Park, I.; Noh, P.; Kim, W.J.; Yang, S.; Moon, B.C. Discrimination of Dipsacus asperoides and D. japonicus based on the analysis of ITS2 DNA barcode sequences. Korean Herb. Med. Inf. 2017, 5, 21-29.

54. Bell, C.D. Preliminary phylogeny of Valerianaceae (Dipsacales) inferred from nuclear and chloroplast DNA sequence data. Mol. Phylogenet. Evol. 2004, 31, 340-350. [CrossRef] [PubMed]

55. Carlson, S.E.; Mayer, V.; Donoghue, M.J. Phylogenetic relationships, taxonomy, and morphological evolution in Dipsacaceae (Dipsacales) inferred by DNA sequence data. Taxon 2009, 58, 1075-1091.

56. Yao, H.; Song, J.; Liu, C.; Luo, K.; Han, J.; Li, Y.; Pang, X.; Xu, H.; Zhu, Y.; Xiao, P. Use of ITS2 region as the universal DNA barcode for plants and animals. PLoS ONE 2010, 5, e13102. [CrossRef] [PubMed] 
57. Kato, H.; Oginuma, K.; GU, Z.; Hammel, B.; Tobe, H. Phylogenetic relationships of Betulaceae based on matK sequences with particular reference to the position of Ostryopsis. Acta Phytotaxon. Geobot. 1999, 49, 89-97.

58. Käss, E.; Wink, M. Phylogenetic relationships in the Papilionoideae (Family leguminosae) based on nucleotide sequences of cpDNA ( $r b c L$ ) and ncDNA (ITS 1 and 2). Mol. Phylogenet. Evol. 1997, 8, 65-88. [CrossRef] [PubMed]

59. Hall, T.A. Bioedit: A user-friendly biological sequence alignment editor and analysis program for windows 95/98/nt. Nucleic Acid Symp. Ser. 1999, 41, 95-98.

60. Librado, P.; Rozas, J. Dnasp v5: A software for comprehensive analysis of DNA polymorphism data. Bioinformatics 2009, 25, 1451-1452. [CrossRef] [PubMed]

61. Delcher, A.L.; Salzberg, S.L.; Phillippy, A.M. Using mummer to identify similar regions in large sequence sets. Curr. Protoc. Bioinform. 2003. [CrossRef] [PubMed]

62. Luo, R.; Liu, B.; Xie, Y.; Li, Z.; Huang, W.; Yuan, J.; He, G.; Chen, Y.; Pan, Q.; Liu, Y.; et al. Soapdenovo2: An empirically improved memory-efficient short-read de novo assembler. Gigascience 2012, 1, 18. [CrossRef] [PubMed]

63. Li, H.; Durbin, R. Fast and accurate long-read alignment with burrows-wheeler transform. Bioinformatics 2010, 26, 589-595. [CrossRef] [PubMed]

64. Tillich, M.; Lehwark, P.; Pellizzer, T.; Ulbricht-Jones, E.S.; Fischer, A.; Bock, R.; Greiner, S. Geseq-Versatile and accurate annotation of organelle genomes. Nucleic Acids Res. 2017, 45, W6-W11. [CrossRef] [PubMed]

65. Carver, T.; Berriman, M.; Tivey, A.; Patel, C.; Bohme, U.; Barrell, B.G.; Parkhill, J.; Rajandream, M.A. Artemis and act: Viewing, annotating and comparing sequences stored in a relational database. Bioinformatics 2008, 24, 2672-2676. [CrossRef] [PubMed]

66. Lowe, T.M.; Eddy, S.R. Trnascan-se: A program for improved detection of transfer RNA genes in genomic sequence. Nucleic Acids Res. 1997, 25, 955-964. [CrossRef] [PubMed]

67. Gurusaran, M.; Ravella, D.; Sekar, K. Repex: Repeat extractor for biological sequences. Genomics 2013, 102, 403-408. [CrossRef] [PubMed]

68. Lohse, M.; Drechsel, O.; Bock, R. OrganellarGenomeDRAW (OGDRAW): A tool for the easy generation of high-quality custom graphical maps of plastid and mitochondrial genomes. Curr. Genet. 2007, 52, 267-274. [CrossRef] [PubMed]

69. Tamura, K.; Stecher, G.; Peterson, D.; Filipski, A.; Kumar, S. Mega6: Molecular evolutionary genetics analysis version 6.0. Mol. Biol. Evol. 2013, 30, 2725-2729. [CrossRef] [PubMed]

70. Yang, Z. PAML 4: Phylogenetic analysis by maximum likelihood. Mol. Biol. Evol. 2007, 24, $1586-1591$. [CrossRef] [PubMed]

71. Thiel, T. Misa-Microsatellite Identification Tool. 2003. Available online: http://pgrc.ipk-gatersleben.de/ misa / (accessed on 17 May 2018).

72. Benson, G. Tandem repeats finder: A program to analyze DNA sequences. Nucleic Acids Res. 1999, 27, 573-580. [CrossRef] [PubMed]

73. Warburton, P.E.; Giordano, J.; Cheung, F.; Gelfand, Y.; Benson, G. Inverted repeat structure of the human genome: The $\mathrm{x}$-chromosome contains a preponderance of large, highly homologous inverted repeats that contain testes genes. Genome Res. 2004, 14, 1861-1869. [CrossRef] [PubMed]

74. Katoh, K.; Misawa, K.; Kuma, K.; Miyata, T. Mafft: A novel method for rapid multiple sequence alignment based on fast fourier transform. Nucleic Acids Res. 2002, 30, 3059-3066. [CrossRef] [PubMed]

75. Darriba, D.; Taboada, G.L.; Doallo, R.; Posada, D. Jmodeltest 2: More models, new heuristics and parallel computing. Nat. Methods 2012, 9, 772. [CrossRef] [PubMed]

76. Ronquist, F.; Teslenko, M.; van der Mark, P.; Ayres, D.L.; Darling, A.; Hohna, S.; Larget, B.; Liu, L.; Suchard, M.A.; Huelsenbeck, J.P. Mrbayes 3.2: Efficient bayesian phylogenetic inference and model choice across a large model space. Syst. Biol. 2012, 61, 539-542. [CrossRef] [PubMed]

77. Ye, J.; Coulouris, G.; Zaretskaya, I.; Cutcutache, I.; Rozen, S.; Madden, T. Primer-BLAST: A tool to design target-specific primers for polymerase chain reaction. BMC Bioinform. 2012, 13, 134. [CrossRef] [PubMed]

Sample Availability: Samples of D. asper, D. japonicus, and P. umbrosa are available from the authors and the herbarium of KIOM. 